\title{
Coronary Ectasia Is Associated with Impaired Left Ventricular Myocardial Performance in Patients without Significant Coronary Artery Stenosis
}

\author{
Koksal Ceyhan ${ }^{a}$ Fatih Koc $^{a} \quad$ Kurtulus Ozdemir $^{\mathrm{b}} \quad$ Atac Celik $^{\mathrm{a}}$ Fatih Altunkas $^{\mathrm{a}}$ \\ Metin Karayakalia Hasan Kadi ${ }^{a}$ Ahmet Ozturk ${ }^{a}$ Mehmet Gungor Kaya ${ }^{c}$ \\ Department of Cardiology, aSchool of Medicine, Gaziosmanpasa University, Tokat, ${ }^{b}$ Selcuk University, Konya, and \\ 'Erciyes University, Kayseri, Turkey
}

\section{Key Words}

Myocardial performance index $\cdot$ Tissue Doppler

echocardiography $\cdot$ Coronary artery ectasia

\begin{abstract}
Objectives: To determine both ventricular functions and tissue Doppler echocardiography (TDE)-derived myocardial performance index (MPI) in patients with coronary artery ectasia (CAE). Subjects and Methods: Twenty-five patients with CAE (13 men; mean age $57 \pm 9$ years) and 25 age- and sex-matched controls without CAE (8 men; mean age $54 \pm$ 10 years) were enrolled in the study. Left and right ventricular functions were detected using conventional echocardiography and TDE. Results: Left ventricle-lateral wall $(0.61 \pm 0.17$; $0.50 \pm 0.10, p=0.02)$, interventricular septum (0.66 \pm 0.17 ; $0.52 \pm 0.10, \mathrm{p}=0.007)$ and mean MPI $(0.63 \pm 0.15 ; 0.51 \pm$ $0.09, p=0.004$ ) were increased in the CAE group compared to the control group. Right ventricular MPI was similar in both the CAE and control groups $(0.58 \pm 0.18 ; 0.52 \pm 0.19$, $p>0.05)$. Conclusion: The findings show that left ventricular $\mathrm{MPI}$ is different in CAE patients without obstructive coronary artery disease compared to the normal control group. Also in these patients, right ventricular MPI was similar to the control group.

Copyright $\odot 2011$ S. Karger AG, Basel
\end{abstract}

\section{Introduction}

Coronary artery ectasia (CAE) is a rare disease compared to other coronary artery abnormalities and it is characterized by a section of dilated artery that is 1.5 -fold or more wider than normal segments [1]. Variable reports state that the CAE incidence is $0.3-4.9 \%$ in the general population [2]. While approximately half of CAE is due to atherosclerosis, $20-30 \%$ is congenital and $10-20 \%$ of the patients with CAE have inflammatory or connective tissue diseases [3]. Isolated CAE, without coronary stenosis and other heart diseases, is rare, occurring in 0.1$0.79 \%$ of patients according to angiographic measurements $[4,5]$. The clinical symptoms of patients with isolated CAE vary greatly and may include exercise angina, atypical angina or myocardial infarction [6-8]. Although myocardial ischemia and left ventricular dysfunction have been found in patients with CAE who have no narrowness or obstruction in the coronary arteries, the ventricular function of these patients has not been well studied $[5,6]$. The left ventricular functions and diastolic parameters of a small set of patients with CAE and no obstructive coronary artery disease have been evaluated by conventional and tissue Doppler echocardiography (TDE) and compared to controls [9]. Nevertheless, to our

\section{KARGER}

Fax +4161306 1234 E-Mail karger@karger.ch www.karger.com
Fatih Koc, MD

Department of Cardiology

Gaziosmanpaşa University School of Medicine

TR-60100 Tokat (Turkey)

Tel. +90 555464 1141, E-Mail drfatkoc@gmail.com 
knowledge, there has been no measurement of the myocardial performance index (MPI) to globally evaluate ventricular functions in patients with CAE. Equally important, right ventricular function, which is a prognostic indicator for most heart diseases [10, 11], has not been studied in patients with CAE. In this study, we aimed to determine both ventricular functions and TDE-derived MPI in patients with CAE.

\section{Subjects and Methods}

\section{Study Population}

We enrolled 25 patients with CAE who underwent coronary angiography after having typical angina and/or who had CAE (13 males; mean age $57 \pm 9$ years) and 25 age- and sex-matched controls without CAE who underwent elective coronary angiography (8 males; mean age $54 \pm 10$ years). Approval was obtained from the institution's ethics committee for this study and all the enrolled patients gave informed consent. Patients with occlusive coronary artery disease, acute coronary syndrome, cardiopathies, congenital heart diseases, cardiac valve diseases, ventricular hypertrophy, branch blocks, ventricular pre-excitation and atrioventricular conduction abnormalities, severe systemic diseases or bad electrocardiographic windows were excluded from the study.

\section{Coronary Angiography}

Coronary angiography was performed on all the patients using the General Electric (GE) Innova 3100 (Milwaukee, Wisc., USA), with the standard Judkins technique without applying nitroglycerin. Two cardiologists (K.C. and A.C.) evaluated the coronary angiographies without knowing the clinical or routine biochemistry results of the patients. When there was no identifiable adjacent normal segment, the mean diameter of the corresponding coronary segment in the control group served as the normal value. The coronary flow rates of all subjects were measured using the thrombolysis in myocardial infarction (TIMI) frame count method as described for left anterior descending, circumflex, and right coronary arteries.

\section{Echocardiography}

Two-dimensional pulsed-wave Doppler and TDE were performed for all patients using a 2.5-MHz transducer (Philips, EnVisor C Ultrasound, Bothell, Wash., USA) in the left decubitus position during normal respiration according to the recommendations of American Society of Echocardiograpgy [12]. The diameters of the left ventricular and the thicknesses of diastolic walls were measured from the parasternal window with two-dimensional M-mode echocardiography. Left ventricular ejection fraction was calculated using the modified Simpson's method [13]. From the apical four-chamber view, Doppler recordings were obtained with the pulsed sample volume placed at the tip of the mitral leaflets. The peak early (E) and late (A) velocities, E-wave deceleration time (DT) and isovolumetric relaxation time (IVRT) were measured. Pulmonary venous flow was taken from the apical 4-chamber view by placing the pulsed-wave Doppler sample volume $1 \mathrm{~cm}$ into the right upper pulmonary vein. The venous peak systolic velocities (Ps) and the pulmonary peak diastolic velocity (Pd) were measured and Ps/Pd ratio was calculated.

Pulsed-wave TDE parameters were measured by an echocardiographic device with active TDE functions (Philips, EnVisor C Ultrasound). The filter settings and gains were adjusted to the minimal optimal level to reduce noise and eliminate the signals produced by the flows. A $3.5-\mathrm{mm}$ sample volume was used. The TDE cursor was placed from the apical 4-chamber view on the mitral annulus opposite the septal and lateral walls and on the region where the tricuspid valve binds to the leaflet of the tricuspid annulus. A Doppler velocity range of -20 to $20 \mathrm{~cm} / \mathrm{s}$ was selected and the velocities were measured online at a sweep of 100 $\mathrm{mm} / \mathrm{s}$. Peak systolic velocity (Sm), peak early (Em) and late (Am) diastolic velocities for each segment were measured and the Em/ Am ratio was calculated. The isovolumetric relaxation time (IRT) was measured from the end of Sm to the beginning of Em, the isovolumetric contraction time (ICT) was measured from the end of Am to the beginning of Sm and the time period of Sm was measured as the ejection time (ET). The MPI was calculated using the equation (ICT+IRT)/ET. The Sm, Em and Am values obtained from tricuspid annulus were used for the right ventricular MPI. The average of the Sm, Em and Am time intervals obtained from the mitral annulus-lateral and interventricular septum was used to calculate left ventricular mean MPI. All Doppler parameters were obtained by calculating the mean of 5 consecutive cycles. Echocardiography measurements were made by the same cardiologist (F.K.) who was blinded to the clinical and angiographic features of the patients. Intraobserver variability was assessed in 10 by repeating the measurements on 2 occasions (7-10 days apart) under similar basal status. Variability was calculated as mean percent error, which was derived as the difference between the 2 averaged data sets of measurements, divided by the mean.

\section{Statistical Analysis}

Continuous variables are expressed as mean \pm standard deviation $(\mathrm{SD})$ and categorical variables are given as percentage. The Kolmogorov-Smirnov test was used to evaluate whether the distribution of variables was normal. A two independent sample $t$ test or Mann-Whitney $U$ test was used to compare continuous variables between 2 groups. The $\chi^{2}$ test, $\chi^{2}$ with continuity correction or Fisher's exact test were applied for the categorical variables when necessary. SPSS software 15.0 for Windows (Chicago, Ill., USA) was used for all statistical analysis. Calculated p values were considered statistically significant when they were $<0.05$.

\section{Results}

The intra-observer variability was $<6 \%$. The baseline characteristics of the CAE and control groups are shown in table 1. Age, sex, blood pressures, heart rates, body mass index, fasting serum glucoses, lipid profiles, hypertension, diabetes mellitus, and coronary artery disease risk factors and current medications were similar $(\mathrm{p}>$ 0.05). 


\section{Coronary Angiography}

Two patients had CAE in all major coronary arteries including the left anterior descending, circumflex and right coronary arteries; 9 had only right CAE; 7 had only left anterior descending artery ectasia, and 2 patients had only circumflex artery ectasia; 3 patients had ectasia in the right coronary and the left anterior descending arteries, 1 patient had ectasia in the circumflex and left anterior descending arteries, and 1 patient had ectasia in the circumflex and right coronary arteries. All coronary arteries were normal in the control group. Coronary spasm, ectasia, plaque or stenoses were not observed in the control group.

\section{Two-Dimensional M-Mode and Pulsed-Wave Doppler} Echocardiography

Two-dimensional echocardiography and pulsed-wave Doppler parameters of the left ventricle for CAE and control group are shown in table 2. Left ventricular IVRT was higher in the CAE group compared to control group (87 $\pm 14 ; 76 \pm 14, \mathrm{p}=0.02)$ and the ratio of $\mathrm{E} / \mathrm{A}$ was lower in the CAE group compared to the control group ( $0.76 \pm$ $0.23 ; 0.92 \pm 0.33, \mathrm{p}=0.03)$. There was no significant difference for the other parameters $(\mathrm{p}>0.05)$.

\section{Tissue Doppler Echocardiography}

The parameters obtained from the left and right ventricles by TDE are shown in table 3. Left ventricular lateral wall $\mathrm{Sm}, \mathrm{Em}, \mathrm{Am}$ and $\mathrm{Em} / \mathrm{Am}$ were similar in both the CAE and control groups ( $p>0.05)$. Am at the left ventricular interventricular septum was higher in the CAE group compared to the control group (12.0 $\pm 2.2 ; 10.3 \pm$ $1.8, \mathrm{p}=0.005)$ and the Em/Am ratio was lower (0.56 \pm $0.13 ; 0.73 \pm 0.24, \mathrm{p}=0.003)$. The mean $\mathrm{Em} / \mathrm{Am}$ ratio of the left ventricle was lower in the CAE group compared to control group $(0.65 \pm 0.17 ; 0.82 \pm 0.31, \mathrm{p}=0.03)$. Right ventricular $\mathrm{Sm}$, Em and Am were similar in both the CAE and control groups ( $\mathrm{p}>0.05)$, and the Em/Am was lower in CAE group compared to control group $(0.54 \pm 0.20$; $0.67 \pm 0.22, \mathrm{p}=0.04)$.

\section{MPI and Time Intervals by TDE}

The MPI and time intervals measured in the left and right ventricles using TDE are shown in table 4. Left ventricular lateral wall ICT, IRT and ET were similar in both the CAE and control group ( $p>0.05)$ and MPI was increased in the CAE group compared to control group $(0.61 \pm 0.17 ; 0.50 \pm 0.10, p=0.02)$. Left ventricle interventricular septum ICT and ET were similar in both the CAE and control groups ( $p>0.05)$ and IRT and MPI were
Table 1. Demographic and angiographic characteristics in CAE and control groups

\begin{tabular}{|c|c|c|c|}
\hline Characteristics & $\begin{array}{l}\text { CAE } \\
(n=25)\end{array}$ & $\begin{array}{l}\text { Controls } \\
(\mathrm{n}=25)\end{array}$ & $\mathrm{p}$ \\
\hline Age, years & $57 \pm 9$ & $54 \pm 10$ & NS \\
\hline Sex, male/female & $13 / 12$ & $8 / 17$ & NS \\
\hline Systolic blood pressure, $\mathrm{mm} \mathrm{Hg}$ & $132 \pm 32$ & $124 \pm 22$ & NS \\
\hline Diastolic blood pressure, $\mathrm{mm} \mathrm{Hg}$ & $82 \pm 14$ & $77 \pm 11$ & NS \\
\hline Heart rate, beats/min & $72 \pm 15$ & $75 \pm 12$ & NS \\
\hline Body mass index & $32 \pm 5$ & $30 \pm 4$ & NS \\
\hline Diabetes mellitus & $5(20)$ & $5(20)$ & NS \\
\hline Hypertension & $14(56)$ & $11(44)$ & NS \\
\hline Family history & $6(24)$ & $3(12)$ & NS \\
\hline Smoking & $6(24)$ & $3(12)$ & NS \\
\hline Fasting serum glucose, $\mathrm{mg} / \mathrm{dl}$ & $110 \pm 46$ & $102 \pm 13$ & NS \\
\hline Total cholesterol, mg/dl & $201 \pm 45$ & $202 \pm 47$ & NS \\
\hline HDL-cholesterol, mg/dl & $42 \pm 10$ & $44 \pm 11$ & NS \\
\hline LDL-cholesterol, mg/dl & $129 \pm 32$ & $130 \pm 37$ & NS \\
\hline Triglycerides, mg/dl & $171 \pm 74$ & $157 \pm 74$ & NS \\
\hline \multicolumn{4}{|l|}{ Medications } \\
\hline Aspirin & $14(56)$ & $10(40)$ & NS \\
\hline ACEI/ARB & $12(48)$ & $8(32)$ & NS \\
\hline Beta blockers & $12(48)$ & $7(28)$ & NS \\
\hline Calcium antagonists & $3(12)$ & $2(8)$ & NS \\
\hline Nitrates & $2(8)$ & $3(12)$ & NS \\
\hline Statin & $11(44)$ & $5(20)$ & 0.07 \\
\hline \multicolumn{4}{|l|}{ Distribution of ectasia } \\
\hline LAD & $14(56)$ & - & - \\
\hline $\mathrm{LCx}$ & $6(24)$ & - & - \\
\hline RCA & $14(56)$ & - & - \\
\hline Number of ectasic vessels & & - & - \\
\hline One vessel & $18(72)$ & - & - \\
\hline Two vessels & $5(20)$ & - & - \\
\hline Three vessels & $2(8)$ & - & - \\
\hline TFC mean & $38 \pm 9$ & $25 \pm 2$ & 0.001 \\
\hline
\end{tabular}

Values are means \pm SD or numbers with percentages in parentheses. ACEI = Angiotensin-converting enzyme inhibitor; $\mathrm{ARB}=$ angiotensin II receptor blocker; $\mathrm{LAD}=$ left anterior descending artery; LCx = left circumflex artery; RCA = right coronary artery; TFC = TIMI frame count; NS = not significant.

higher in the CAE group compared to the control group (IRT: $97 \pm 19 ; 83 \pm 16, \mathrm{p}=0.01$ and MPI: $0.66 \pm 0.17$; $0.52 \pm 0.10, \mathrm{p}=0.007$, respectively). Left ventricular mean IRT, ICT and MPI were higher in the CAE group compared to the control group (IRT: $89 \pm 14 ; 79 \pm 16$, $\mathrm{p}=0.03$, ICT: $79 \pm 20 ; 66 \pm 17, \mathrm{p}=0.04$, MPI: $0.63 \pm$ $0.15 ; 0.51 \pm 0.09, \mathrm{p}=0.004$, respectively) however, ET was lower in the CAE group compared to the control group $(270 \pm 29 ; 287 \pm 26, p=0.05)$. Right ventricular ICT, IRT, ET and MPI were similar in both the CAE and control groups $(\mathrm{p}>0.05)$. 
Table 2. Two-dimensional M-mode and pulsed-wave Doppler echocardiography in CAE and control groups

\begin{tabular}{lccl}
\hline $\begin{array}{l}\text { Measured } \\
\text { functions }\end{array}$ & $\begin{array}{l}\text { CAE } \\
(\mathrm{n}=25)\end{array}$ & $\begin{array}{l}\text { Controls } \\
(\mathrm{n}=25)\end{array}$ & $\mathrm{p}$ \\
\hline LVEDD, cm & $4.9 \pm 0.6$ & $4.8 \pm 0.4$ & $\mathrm{NS}$ \\
LVESD, cm & $3.0 \pm 0.6$ & $2.9 \pm 0.7$ & $\mathrm{NS}$ \\
IVS, cm & $1.1 \pm 0.2$ & $1.0 \pm 0.2$ & $\mathrm{NS}$ \\
$\mathrm{PW}, \mathrm{cm}$ & $1.0 \pm 0.2$ & $0.9 \pm 0.1$ & $\mathrm{NS}$ \\
$\mathrm{EF}, \%$ & $62 \pm 6$ & $60 \pm 6$ & $\mathrm{NS}$ \\
$\mathrm{E}, \mathrm{cm} / \mathrm{s}$ & $61 \pm 17$ & $72 \pm 22$ & 0.06 \\
$\mathrm{~A}, \mathrm{~cm} / \mathrm{s}$ & $82 \pm 16$ & $83 \pm 29$ & $\mathrm{NS}$ \\
E/A & $0.76 \pm 0.23$ & $0.92 \pm 0.33$ & 0.03 \\
DT, ms & $214 \pm 48$ & $198 \pm 44$ & $\mathrm{NS}$ \\
IVRT, ms & $87 \pm 14$ & $76 \pm 14$ & 0.02 \\
Ps/Pd & $1.5 \pm 0.6$ & $1.2 \pm 0.4$ & $\mathrm{NS}$ \\
\hline
\end{tabular}

Values are means \pm SD. LVEDD $=$ Left ventricular end-diastolic diameter; LVESD = left ventricular end-systolic diameter; IVS = interventricular septum; $\mathrm{PW}=$ posterior wall; $\mathrm{EF}=$ ejection fraction; $\mathrm{E}=$ early diastolic mitral inflow velocity; $\mathrm{A}=$ late diastolic mitral inflow velocity; DT = deceleration time of the mitral valve; $\mathrm{Ps}=$ pulmonary vein systolic velocity; $\mathrm{Pd}=$ pulmonary vein diastolic velocity; IVRT = isovolumetric relaxation time; $\mathrm{NS}=$ not significant.

Table 3. TDE in CAE and control groups

\begin{tabular}{lccl}
\hline Measure functions & $\begin{array}{l}\text { CAE } \\
(\mathrm{n}=25)\end{array}$ & $\begin{array}{l}\text { Controls } \\
(\mathrm{n}=25)\end{array}$ & $\mathrm{p}$ \\
\hline Lateral & & & \\
$\mathrm{Sm}, \mathrm{cm} / \mathrm{s}$ & $8.7 \pm 2.0$ & $9.5 \pm 1.8$ & $\mathrm{NS}$ \\
$\mathrm{Em}, \mathrm{cm} / \mathrm{s}$ & $8.7 \pm 2.7$ & $9.9 \pm 2.6$ & $\mathrm{NS}$ \\
$\mathrm{Am}, \mathrm{cm} / \mathrm{s}$ & $11.6 \pm 2.1$ & $11.7 \pm 2.7$ & $\mathrm{NS}$ \\
Em/Am & $0.77 \pm 0.27$ & $0.93 \pm 0.44$ & $\mathrm{NS}$ \\
Interventricular septum & & & \\
Sm, cm/s & $8.1 \pm 2.3$ & $8.1 \pm 1.2$ & $\mathrm{NS}$ \\
$\mathrm{Em}, \mathrm{cm} / \mathrm{s}$ & $6.7 \pm 2.2$ & $7.3 \pm 2.0$ & $\mathrm{NS}$ \\
$\mathrm{Am}, \mathrm{cm} / \mathrm{s}$ & $12.0 \pm 2.2$ & $10.3 \pm 1.8$ & 0.005 \\
$\mathrm{Em} / \mathrm{Am}$ & $0.56 \pm 0.13$ & $0.73 \pm 0.24$ & 0.003 \\
LV mean & & & \\
$\mathrm{Sm}, \mathrm{cm} / \mathrm{s}$ & $8.3 \pm 2.0$ & $8.8 \pm 1.2$ & $\mathrm{NS}$ \\
$\mathrm{Em}, \mathrm{cm} / \mathrm{s}$ & $7.7 \pm 2.1$ & $8.6 \pm 2.0$ & $\mathrm{NS}$ \\
$\mathrm{Am}, \mathrm{cm} / \mathrm{s}$ & $11.7 \pm 1.3$ & $11.0 \pm 1.7$ & $\mathrm{NS}$ \\
$\mathrm{Em} / \mathrm{Am}$ & $0.65 \pm 0.17$ & $0.82 \pm 0.31$ & 0.03 \\
$\mathrm{RV}$ & & & \\
$\mathrm{Sm}, \mathrm{cm} / \mathrm{s}$ & $13.2 \pm 2.8$ & $12.5 \pm 2.5$ & $\mathrm{NS}$ \\
$\mathrm{Em}, \mathrm{cm} / \mathrm{s}$ & $7.6 \pm 2.2$ & $8.9 \pm 2.7$ & 0.06 \\
$\mathrm{Am}, \mathrm{cm} / \mathrm{s}$ & $14.8 \pm 3.1$ & $13.8 \pm 3.0$ & $\mathrm{NS}$ \\
$\mathrm{Em} / \mathrm{Am}$ & $0.54 \pm 0.20$ & $0.67 \pm 0.22$ & 0.04 \\
\hline
\end{tabular}

Values are means \pm SD. Sm = Systolic myocardial velocity; $\mathrm{Em}=$ early myocardial velocity; Am = late myocardial velocity; $\mathrm{LV}=$ left ventricle; $\mathrm{RV}=$ right ventricle; $\mathrm{NS}$ = not significant.
Table 4. MPI and time intervals by TDE in CAE and control groups

\begin{tabular}{lccl}
\hline Parameters & $\begin{array}{l}\text { CAE } \\
(\mathrm{n}=25)\end{array}$ & $\begin{array}{l}\text { Controls } \\
(\mathrm{n}=25)\end{array}$ & $\mathrm{p}$ \\
\hline Lateral & & & \\
$\quad$ ICT, ms & $81 \pm 24$ & $69 \pm 23$ & $\mathrm{NS}$ \\
$\quad$ IRT, ms & $81 \pm 18$ & $74 \pm 18$ & $\mathrm{NS}$ \\
$\quad$ ET, ms & $271 \pm 29$ & $287 \pm 26$ & 0.06 \\
$\quad$ MPI & $0.61 \pm 0.17$ & $0.50 \pm 0.10$ & 0.02 \\
Interventricular septum & & & \\
$\quad$ ICT, ms & $76 \pm 24$ & $64 \pm 15$ & 0.06 \\
$\quad$ IRT, ms & $97 \pm 19$ & $83 \pm 16$ & 0.01 \\
$\quad$ ET, ms & $268 \pm 31$ & $286 \pm 27$ & 0.05 \\
$\quad$ MPI & $0.66 \pm 0.17$ & $0.52 \pm 0.10$ & 0.007 \\
LV mean & $79 \pm 20$ & $66 \pm 17$ & 0.04 \\
$\quad$ ICT, ms & $89 \pm 14$ & $79 \pm 16$ & 0.03 \\
IRT, ms & $270 \pm 29$ & $287 \pm 26$ & 0.05 \\
$\quad$ ET, ms & $0.63 \pm 0.15$ & $0.51 \pm 0.09$ & 0.004 \\
$\quad$ MPI & & & \\
RV & $70 \pm 25$ & $61 \pm 15$ & NS \\
ICT, ms & $83 \pm 34$ & $74 \pm 32$ & NS \\
IRT, ms & $267 \pm 34$ & $270 \pm 35$ & NS \\
ET, ms & $0.58 \pm 0.18$ & $0.52 \pm 0.19$ & NS \\
$\quad$ MPI & & &
\end{tabular}

Values are means $\pm \mathrm{SD}$. ICT $=$ Isovolumetric contraction time; IRT = isovolumetric relaxation time; ET = ejection time; $\mathrm{LV}=$ left ventricle; $\mathrm{RV}=$ right ventricle; $\mathrm{NS}=$ not significant.

\section{Discussion}

The most common symptom of CAE is effort-induced angina and it can occur without significant coronary stenosis [6]. Demopoulos et al. [14] found that there is a similar incidence of angina pectoris in patients with isolated CAE compared to patients with significant coronary artery stenosis. Impaired coronary blood flow, which is defined as delayed antegrade dye filling, a segmental back flow, or deposition of dye in the coronary artery on coronary arteriography, were also postulated to be possible symptoms of myocardial ischemia in CAE patients $[6,15]$. In a study by Papadakis et al. [16] coronary flow velocity was measured using the TIMI frame count method and it was found to be lower in patients with CAE than both the obstructive CAD and control groups. The TIMI frame count method is a simple technique used to evaluate the quantitative index of coronary blood flow [17]. Kosar et al. [18] found a higher TIMI frame count in patients with CAE compared to the control group. Our study confirmed these findings as the TIMI frame count was significantly higher in patients 
with CAE compared to the control group. Gulec et al. [19] used microvascular perfusion through the myocardial blush technique to evaluate and compare normal and ectasic segments of vessels in patients with isolated $\mathrm{CAE}$ and in controls. They found microvascular perfusion defects in ectasic segments that was hypothesized to affect left ventricular systolic and diastolic parameters and to reduce ventricular performance. In our study, left ventricular MPI of the CAE patients was significantly higher than the normal control group. This result confirms the findings of Gulec et al. [19]. Diastolic disorders in ischemic heart diseases are seen earlier than systolic dysfunctions [20]. Patients with coronary artery disease have reduced mitral E velocity and E/A ratio and ventricular relaxation delay compared to an age-matched age control group [21]. In our study, mitral E/A ratio of the CAE patients was significantly lower than the control group. Myocardial velocities obtained using TDE are considered to be the new parameters to evaluate left ventricular functions [22]. The Em/Am ratio and Em velocity are reduced in patients with disordered left ventricular relaxation [23]. In this study, the left ventricular Em/ Am ratio was significantly lower in the CAE group than the control group. Also, the right ventricular Em/Am ratio was significantly lower in the CAE group than the control group. Moreover, it has been found that Sm, Em and $\mathrm{Am}$ in coronary artery disease patients are related to mortality [24]. In our study, left ventricular interventricular septum Am velocity of the CAE group was significantly higher than the control group. Doppler-derived MPI is calculated by dividing the sum of the ICT and the IRT by the ET. MPI is a simple, reproducible, and noninvasive method to assess systolic and diastolic functions $[25,26]$. Also, MPI is related to left ventricular dysfunc- tion and clinical severity of heart failure and is a powerful parameter for the prognostic assessment of these patients [27]. It has been previously shown that increased Doppler-derived MPI is related to mortality in a variety of cardiac diseases [28]. Ozdemir et al. [28] have shown in their study that while Doppler-derived MPI is affected by preload and heart rate, TDE-derived MPI is not affected by either. In our study, left ventricular lateral wall, interventricular septum and mean MPI was significantly higher in CAE patients than the control group. However, right ventricular MPI was shown to be similar to the control group.

This study has some limitations. First, relatively few patients were included in this study, so the number of participating centers should be increased and the results should be confirmed with more comprehensive studies. Second, overall medications may influence the results between experimental and control groups. Previous studies show that $\beta$-blockers, in addition to ACE inhibitors or ARBs, have beneficial effects on left ventricular remodeling [29]. Nearchou et al. [30] reported that ACE inhibitor therapy improved ventricle performance and Tei index during the early phase of inferior acute myocardial infarction. However, in our study, there was no significant difference in the medications.

\section{Conclusion}

Due to these findings, we propose that CAE is not a benign phenomenon occurring coincidentally during coronary angiography but that it is an important clinical situation requiring aggressive risk stratification even in the absence of obstructive coronary artery disease.

\section{References}

1 Hartnell GG, Parnell BM, Pridie RB: Coronary artery ectasia. Its exercise induced myocardial ischemia in isolated coronary artery prevalence and clinical significance in 4,993 patients. Br Heart J 1985;54:392-395.

-2 Manginas A, Cokkinos DV: Coronary artery ectasias: imaging, functional assessment and clinical implications. Eur Heart J 2006;27: 1026-1031.

3 Seabra-Gomes R, Somerville J, Ross DN, Emanuel R, Parker DJ, Wong M: Congenital coronary artery aneurysms. Br Heart J 1974; 36:329-335

$\checkmark 4$ Swaye PS, Fisher LD, Litwin P, Vignola PA, Judkins MP, Kemp HG, Mudd JG, Gosselin
AJ: Aneurysmal coronary artery disease. Circulation 1983;67:134-138.

5 Al-Harthi SS, Nouh MS, Arafa M, al-Nozha M: Aneurysmal dilatation of the coronary arteries: diagnostic patterns and clinical significance. Int J Cardiol 1991;30:191-194.

-6 Krüger D, Stierle U, Herrmann G, Simon R, Sheikhzadeh A: Exercise-induced myocardial ischemia in isolated coronary artery ectasias and aneurysms ('dilated coronopathy'). J Am Coll Cardiol 1999;34:14611470 .

7 Befeler B, Aranda MJ, Embi A, Mullin FL, El-Sherif N, Lazzara R: Coronary artery aneurysms: study of their etiology, clinical course and effect on left ventricular function and prognosis. Am J Med 1977;62:597-607.

$\checkmark 8$ Rath S, Har-Zahav Y, Battler A, Agranat O, Rotstein Z, Rabinowitz B, Neufeld HN: Fate of nonobstructive aneurysmatic coronary artery disease: angiographic and clinical follow-up report. Am Heart J 1985;109:785791.

-9 Saglam M, Barutcu I, Karakaya O, Esen AM, Akgun T, Karavelioglu Y, Karapinar H, Turkmen M, Ozdemir N, Kaymaz C: Assessment of left ventricular functions in patients with isolated coronary artery ectasia by conventional and tissue Doppler imaging. Angiology 2008;59:306-311. 
10 Polak JF, Holman BL, Wynne J, Colucci WS: Right ventricular ejection fraction: an indicator of increased mortality in patients with congestive heart failure associated with coronary artery disease. J Am Coll Cardiol 1983; 2:217-224.

-11 DiSalvo TG, Mathier M, Semigran MJ, Dec GW, DiSalvo TG: Preserved right ventricular ejection fraction predicts exercise capacity and survival in advanced heart failure. J Am Coll Cardiol 1995;25:1143-1153.

- 12 Pearlman AS, Gardin JM, Martin RP, Parisi AF, Popp RL, Quinones MA, Stevenson JG: Guidelines for optimal physician training in echocardiography recommendations of the American Society of Echocardiography Committee for Physician training in Echocardiography. Am J Cardiol 1987;60:158163.

-13 Schiller NB, Shah PM, Crawford M, et al: Recommendations for quantitation of the left ventricle by two-dimensional echocardiography. American Society of Echocardiography Committee on Standards, Subcommittee on Quantitation of Two-Dimensional Echocardiograms. J Am Soc Echocardiogr 1989;2:358-367.

- 14 Demopoulos VP, Olympios CD, Fakiolas CN, Pissimissis EG, Economides NM, Adamopoulou E, Foussas SG, Cokkinos DV: The natural history of aneurysmal coronary artery disease. Heart 1997;78:136-141.

15 Tambe AA, Demany MA, Zimmerman Mascarenhas E: Angina pectoris and slow flow velocity of dye in coronary arteries: a new angiographic finding. Am Heart J 1972;84:6671.

-16 Papadakis MC, Manginas A, Cotileas P, De mopoulos V, Voudris V, Pavlides G, Foussas SG, Cokkinos DV: Documentation of slow coronary flow by the TIMI frame count in patients with coronary ectasia. Am J Cardiol 2001;88:1030-1032.
17 Gibson CM, Cannon CP, Daley WL, Dodge JT Jr, Alexander B Jr, Marble SJ, McCabe CH, Raymond L, Fortin T, Poole WK, Braunwald E: TIMI frame count: a quantitative method of assessing coronary artery flow. Circulation 1996;93:879-888

18 Kosar F, Acikgoz N, Sahin I, Topal E, Aksoy Y, Cehreli S: Effect of ectasia size or the ectasia ratio on the thrombosis in myocardial infarction frame count in patients with isolated coronary artery ectasia. Heart Vessels 2005;20:199-202.

19 Gulec S, Atmaca Y, Kilickap M, Akyürek O, Aras O, Oral D: Angiographic assessment of myocardial perfusion in patients with isolated coronary artery ectasia. Am J Cardiol 2003;91:996-999.

20 García-Fernández MA, Azevedo J, Moreno M, Bermejo J, Pérez-Castellano N, Puerta P, Desco M, Antoranz C, Serrano JA, García E, Delcán JL: Regional diastolic function in ischaemic heart disease using pulsed wave Doppler tissue imaging. Eur Heart J 1999;20: 496-505.

21 Ohte N, Narita H, Hashimoto T, Hayano J, Akita S, Kurokawa K: Differentiation of abnormal relaxation pattern with aging from abnormal relaxation pattern with coronary artery disease in transmitral flow with the use of tissue Doppler imaging of the mitral annulus. J Am Soc Echocardiogr 1999;12: 629-635.

22 Ozdemir K, Altunkeser BB, Içli A, Ozdil H, Gok $\mathrm{H}$ : New parameters in identification of right ventricular myocardial infarction and proximal right coronary artery lesion. Chest 2003;124:219-226.

23 Sohn DW, Chai IH, Lee DJ, Kim HC, Kim HS, Oh BH, Lee MM, Park YB, Choi YS, Seo JD, Lee YW: Assessment of mitral annulus velocity by Doppler tissue imaging in the evaluation of left ventricular diastolic function. J Am Coll Cardiol 1997;30:474-480.

-24 Wang M, Yip GW, Wang AY, Zhang Y, Ho PY, Tse MK, Yu CM, Sanderson JE: Tissue Doppler imaging provides incremental prognostic value in patients with systemic hypertension and left ventricular hypertrophy. J Hypertens 2005;23:183-191.
25 Tei C, Ling LH, Hodge DO, Bailey KR, Oh JK, Rodeheffer RJ, Tajik AJ, Seward JB: New index of combined systolic and diastolic myocardial performance: a simple and reproducible measure of cardiac function: a study in normal and dilated cardiomyopathy. J Cardiol 1995;26:357-366.

26 Tavil Y, Kanbay A, Sen N, Ciftçi TU, Abaci A, Yalçin MR, Köktürk O, Cengel A: Comparison of right ventricular functions by tissue Doppler imaging in patients with obstructive sleep apnea syndrome with or without hypertension. Int J Cardiovasc Imaging 2007;23:469-477.

27 Vizzardi E, Chiari E, Faggiano P, D’Aloia A, Bordonali T, Metra M, Cas LD: Measurement of the myocardial performance index in ambulatory patients with heart failure: correlation with other clinical and echocardiographic parameters and independent prognostic value. Echocardiography 2010; 27:123-129.

-28 Ozdemir K, Balci S, Duzenli MA, Can I, Yazici M, Aygul N, Altunkeser BB, Altintepe L, Turk S: Effect of preload and heart rate on the Doppler and tissue Doppler-derived myocardial performance index. Clin Cardiol 2007;30:342-348.

29 Hoshikawa E, Matsumura Y, Kubo T, Okawa M, Yamasaki N, Kitaoka H, Furuno T, Takata J, Doi YL: Effect of left ventricular reverse remodeling on long-term prognosis after therapy with angiotensin-converting enzyme inhibitors or angiotensin II receptor blockers and $\beta$ blockers in patients with idiopathic dilated cardiomyopathy. Am J Cardiol 2011; 107:1065-1070.

30 Nearchou NS, Tsakiris AK, Lolaka MD, Zarcos I, Skoufas DP, Skoufas PD: Influence of perindopril on left ventricular global performance during the early phase of inferior acute myocardial infarction: assessment by Tei index. Echocardiography 2003;20:319327. 